\title{
Chapter 10 Seismic Response of Underground Lifeline Systems
}

\author{
Selçuk Toprak, Engin Nacaroğlu, and A. Cem Koç
}

\begin{abstract}
This paper presents and discusses the recent developments related to seismic performance and assessment of buried pipelines. The experience from the performance of pipelines during last earthquakes provided invaluable information and lead to new developments in the analysis and technologies. Especially, the pipeline performance during Canterbury earthquake sequence in New Zealand is taken as a case study here. The data collected for the earthquake sequence are unprecedented in size and detail, involving ground motion recordings from scores of seismograph stations, high resolution light detection and ranging (LiDAR) measurements of vertical and lateral movements after each event, and detailed repair records for thousands of $\mathrm{km}$ of underground pipelines with coordinates for the location of each repair. One of the important learnings from the recent earthquakes is that some earthquake resistant design and technologies proved to be working. This provides a motivation to increase international exchange and cooperation on earthquake resistant technologies. Another observation is that preventive maintenance is important to reduce the pipeline damage risk from seismic and other hazards. To increase the applicability and sustainability, seismic improvements should be incorporated into the pipe replacement and asset management programs as part of the preventive maintenance concept. However, it is also important to put in the most proper pipeline from the start as replacing or retrofitting the pipelines later requires substantial investment. In this respect, seismic considerations should be taken into account properly in the design phase.
\end{abstract}

\subsection{Introduction}

Observations from recent earthquakes provided opportunities to evaluate the pipeline performances with respect to pipeline properties, soil conditions and different levels of loadings. Earthquake damage to buried pipelines can be attributed to

\footnotetext{
S. Toprak (四) • E. Nacaroğlu • A.C. Koç

Department of Civil Engineering, Pamukkale University, Denizli, Turkey

e-mail: stoprak@pau.edu.tr; enacaroglu@pau.edu.tr; a_c_koc@pau.edu.tr
}

A. Ansal (ed.), Perspectives on European Earthquake Engineering and Seismology, Geotechnical, Geological and Earthquake Engineering 39,

DOI 10.1007/978-3-319-16964-4_10 
transient ground deformation (TGD) or to permanent ground deformation (PGD) or both. TGD occurs as a result of seismic waves and often stated as wave propagation or ground shaking effect. PGD occurs as a result of surface faulting, liquefaction, landslides, and differential settlement from consolidation of cohesionless soil. The effect of earthquake loading on pipelines can be expressed in terms of axial and flexural deformations. At locations where the pipeline is relatively weak because of corrosion, etc., breaks and/or cracks may be observed on the pipelines. If deformations are high, the damages can be in the form of separations of joints, wrinkling, buckling and tearing of pipelines.

There exist many studies which evaluated the effect of earthquakes on buried pipeline systems (Chen et al. 2002; Tromans et al. 2004; Hwang et al. 2004; Scawthorn et al. 2006; Yifan et al. 2008). A comprehensive study for a very large pipeline system can be found in O'Rourke and Toprak (1997) and Toprak (1998) which assess the Los Angeles water supply damage caused by the 1994 Northridge earthquake. A more recent example can be found in Toprak et al. (2014) and O'Rourke et al. $(2012,2014)$ regarding pipeline performance during Canterbury earthquake sequence in New Zealand. Following the 7.1 Mw Sept. 4, 2010 Darfield earthquake, thousands of aftershocks with Mw as high as 6.2 have been recorded in the area of Christchurch, NZ. These earthquakes, termed the Canterbury earthquake sequence are unprecedented in terms of repeated earthquake shocks with substantial levels of ground motion affecting a major city with modern infrastructure. Furthermore, the earthquakes were accompanied by multiple episodes of widespread and severe liquefaction with large PGD levels imposed on underground lifelines during each event. The data collected for the earthquake sequence are likewise unprecedented in size and detail, involving ground motion recordings from scores of seismograph stations, high resolution light detection and ranging (LiDAR) measurements of vertical and lateral movements after each event, and detailed repair records for thousands of $\mathrm{km}$ of underground pipelines with coordinates for the location of each repair.

One of the most critical lessons of the recent earthquakes is the need for seismic planning for lifelines, with appropriate supplies and backup systems for emergency repair and restoration. Seismic planning however requires physical loss estimations before the earthquakes occur. Methodologies for estimating potential pipelines damage use relationships which are often called in different names such as "fragility curves", "damage functions", "vulnerability functions" or "damage relationships". These relationships are primarily empirical and obtained from past earthquakes. Buried pipeline damage correlations are critical part of loss estimation procedures applied to lifelines for future earthquakes. An extensive review of the past pipeline damage relationships primarily for ground shaking (transient ground deformations) can be found in Toprak (1998), Toprak and Taşkın (2007), PinedaPorras and Najafi (2010). Especially, the Northridge earthquake was an important event for a leap in the development of pipeline damage relationships. The substantial earthquake damage in the City of Los Angeles water supply system and availability of the strong motion instruments throughout the area provided a unique opportunity to develop and improve damage correlations. The extensive database 
required use of geographical information systems (GIS) in the assessments. By using this database, Toprak (1998) and O'Rourke et al. (1998) relationships were developed primarily from cast iron (CI) pipeline damage although they made limited comparisons with damage for other pipe types. O'Rourke and Jeon (1999, 2000) went one step ahead and developed separate relationships for CI, ductile iron (DI), asbestos cement (AC), and steel pipelines. They also developed relationships which uses pipe diameter (Dp) and PGV together. Trifunac and Todorovska (1997) developed pipeline damage relationships using the 1994 Northridge earthquake data. Their relationships relate the average number of water pipe breaks per $\mathrm{km}^{2}$ with the peak strain in the soil or intensity of shaking at the site. American Lifelines Alliance (2001) project combined data from 12 US, Japan, and Mexico earthquakes and developed relationships for wave propagation damage. O'Rourke and Deyoe (2004) investigated why there is significant difference between HAZUS relationship and the other relationships developed after the 1994 Northridge earthquake. They concluded that the most significant difference between the data sets is seismic wave type. When plotted on repair rate versus ground strain, it appears that the scatter of data points from Mexico and other earthquakes reduces substantially. In terms of PGV, they introduce two different relationships, one to use in the case of $\mathrm{R}$ waves and the other for S waves. Most recently, O'Rourke et al. $(2012,2014)$ concluded that the Christchurch data for RR vs. PGV follows the trends for AC and CI pipelines observed in previous earthquakes. The data and linear regressions are shown in Fig. 10.1. It is important to include the new data as they become available after earthquakes in order to develop more robust regressions for future fragility analyses of lifeline earthquake performance.

Continuous service of lifeline systems such as drinking water and natural gas pipeline systems or getting their functionality quickly back right after an earthquake is very important and crucial for urban societies. It was observed in the past earthquakes that pipeline damage density was much higher at locations where permanent ground deformations (PGD) were observed. Hence, this paper deals with especially PGD effect evaluations. PGD occurs as a result of surface faulting, liquefaction, landslides and differential settlement from consolidation of cohesionless soils. It is important for utility companies to evaluate their existing systems against PGD effects as well as to design their new systems resistant to these effects. This paper presents the recent developments in the assessment of PGD effects on pipelines.

\subsection{Pipeline Properties and Preventive Maintenance}

Performance of pipelines in past earthquakes showed that the pipe material and joint type are important for the response to earthquake loading. Pipe compositions of pipeline systems may differ in cities and countries. The comparisons of water distribution networks in various countries (e.g., Toprak et al. 2007) show that pipe compositions (including joint types) in the water distribution networks differ 

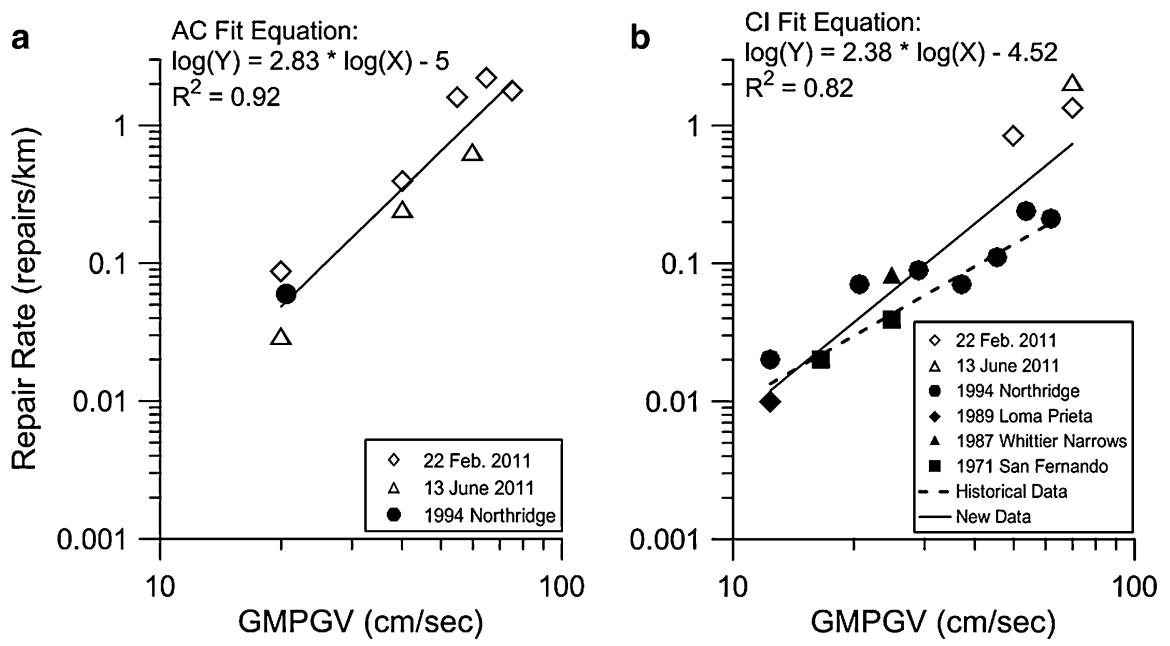

Fig. 10.1 Repair rate vs. GMPGV for (a) AC pipelines and (b) CI pipelines (O'Rourke et al. 2014)

significantly from country to country. The history and development of water supply systems in urban areas of countries affect the existing pipe compositions. For example, the main types of buried water pipes in Japan are ductile cast iron pipes (DIP), grey cast iron pipes (CIP), steel pipes (SP), polyethylene pipes (PE), polyvinyl chloride pipes (PVC), and asbestos cement pipes (ACP). Ductile cast iron pipes account for $60 \%$ of the total length of buried water pipes (Miyajima 2012). Especially, asbestos cement pipes are well known for their high damage rates during earthquakes.

Figure 10.2 shows some typical joint types in Japan water distribution systems. These joints were primarily used in pipelines greater than $300 \mathrm{~mm}$ in diameter (Eidinger 1998). Table 10.1 provides properties of the seismic joints. Types "S" and "S-II" joints are special earthquake resistant joints whereas type $\mathrm{K}$ is a mechanical joint. Type "S" joints have 2-4 cm of flexibility (500-2,600 mm diameter) and type "S-II" joints have 5-7 cm of flexibility (100-450 mm diameter). Type "S" were used until 1980 and type "S-II" were used since 1980. During the 1995 Kobe earthquake, the performance of type "S" joints was average whereas performance of type "S-II" joints was very well. Type K joints didn't performed well. A more recent earthquake resistant joint ductile iron pipe (ERDIP) performed very well in recent earthquakes and selected by Los Angeles Department of Water and Power (LADPW) for pilot applications in USA (Davis 2012). Purpose of the pilot project is to allow the LADWP to become acquainted with the ERDIP, to obtain direct observations and experience of the design and installation procedures, to compare the design and installation of ERDIP with pipes normally installed by LADWP, and to make own assessment on suitability for using the ERDIP to improve network reliability (Miyajima 2012; Davis 2012). 

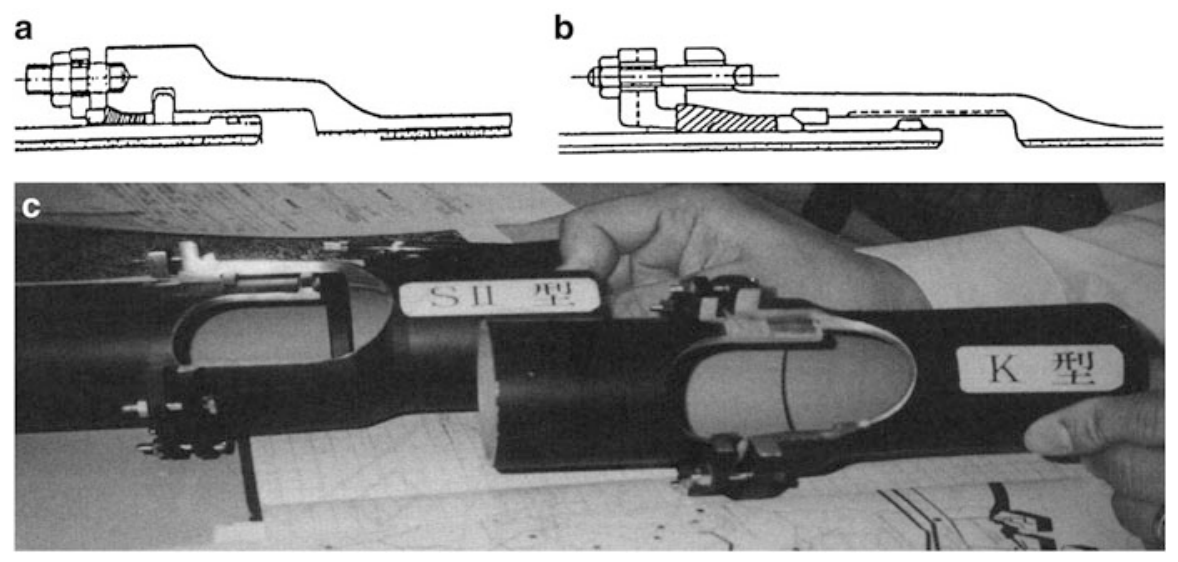

Fig. 10.2 Typical joint types in Japan water distribution systems. (a) S Type Joint. (b) SII Type Joint. (c) SII and K Type Joints (From Eidinger 1998)

Table 10.1 Characteristics of joint types (Miyajima 2012)

\begin{tabular}{l|l}
\hline Joint & Characteristics \\
\hline Type A & $\begin{array}{l}\text { A rectangular rubber gasket is placed around the socket and the joint bolts are } \\
\text { tightened with a gland }\end{array}$ \\
\hline Type T & $\begin{array}{l}\text { A rubber gasket is placed around the socket and the spigot is inserted into the } \\
\text { socket }\end{array}$ \\
\hline Type K & $\begin{array}{l}\text { A modified version of Type A. This has only a rubber gasket which a rectan- } \\
\text { gular one and a round one are combined }\end{array}$ \\
\hline $\begin{array}{l}\text { Type S, Type } \\
\text { S-II }\end{array}$ & $\begin{array}{l}\text { A rubber gasket and a lock ring are placed around the socket and the spigot is } \\
\text { inserted into the socket. The joint has good earthquake resistance with high } \\
\text { elasticity and flexibility and a disengagement prevention mechanism }\end{array}$ \\
\hline Type NS & Same earthquake resistance as Type S but is easier to use than Type S \\
\hline
\end{tabular}

It is important to put in the most proper pipeline from the start as replacing or retrofitting the pipelines later requires substantial investment. Sufficient considerations should be given regarding the pipe materials and joints from the life expectancy and hazards points of view. Buried pipes of distribution systems are worn in the length of time because of the temperature, soil moisture, corrosion and other aging effects (Toprak et al. 2012). For example, aging of pipes in a water distribution system may have three main results. First, aging of pipe material causes a decrease in the strength of pipe. Then pipe breaks are increased at the high pressure areas of the system. Second, aging of a pipe increases the friction coefficient of the pipe so the energy loss in that pipe rises. Then more pumping cost occurs and sometimes a gravity working system needs pumping. Finally, aging of pipes affect the water quality in the system and may cause discolored water. Aging of a pipe is unavoidable but this process may be delayed by some precautions. Cathodic protection for steel pipes, lining and coating for steel and ductile iron pipes are some anti-aging techniques. In the design phase of a water distribution 
system, analyzing the temperature changes in the area, pressure values of the system, chemical components of the soil and ground water helps for the selection of long life pipe material and suitable burial depth of pipes.

Most public water utilities use the concept of "maintenance only when a breakdown occurs". However, in recent years "preventive maintenance" and "proactive management" concept is getting more attraction. The logic behind preventive maintenance (PM) is that it costs far less to regularly schedule downtime and maintenance than it does to operate the network until breakdown at which repair or replacement is imperative. The primary goal of PM is thus to prevent the failure of components of the network before they actually occur by using advanced methods of statistical and risk analysis. The consequences of "maintenance on the run" are unreliable service, customer dissatisfaction, and significant water losses of valuable resources due to leakage or pipe rupture. To take full advantage of this, the utilities must have an accurate topological image of the network, the age and type of materials used in its various branches and past maintenance records.

An interesting project on this topic was presented by Tsakiris et al. (2011) and Toprak et al. (2012). The project is a European project under the Leonardo da Vinci program and entitled "Preventive Maintenance for Water Utility Networks (PM4WAT)". The project consortium was composed of seven organizations from four European countries, all Mediterranean that face similar problems with water resources and distribution (Toprak and Koç 2013). Some of these countries have old and non-homogeneous networks that are subject to ageing, massive water losses, seismic activity and other natural hazards. The consortium includes universities and research institutions, an ICT organization, VET providers and urban utility networks, selected with a view to their knowledge and experience. In particular the project objectives are: to transfer state of the art on preventive maintenance methodologies and practices from domain experts from the participating countries to personnel working in urban water utilities; to develop a training simulation (TS) platform that will advise trainees to estimate the reliability of a network and to examine various "what-if" scenarios; to provide training on pro-active rehabilitation and on the effects of natural hazards; and to develop courseware for web-based and off-line training on preventive maintenance of urban utility networks, made available in the four languages of the participating countries (English, Greek, Italian and Turkish).

The training simulator of the PM4WAT project is based on a Fifth Framework project SEISLINES (Age-Variant Seismic Structural Reliability of Existing Underground Water Pipelines) which was performed between 2000 and 2002 (Becker et al. 2002; Camarinopoulos et al. 2001). The product of SEISLINES was re-designed and adapted for the purposes of PM4WAT project. The training simulator uses real geographical information on the topology of the water utility networks as well as real data on the properties of the elements in the branches of the network. There are four intermittent (surge pressure, frost, seismic and thermal) and four permanent (earth, water, traffic and working pressure) loads considered by the simulator (Camarinopoulos et al. 2001). The original software SEISLINES has been thoroughly revised with the view to simplify the sequence of steps necessary 
to view the water network, select the critical points at which the reliability will be estimated and finally display of the results. The final product was with a userfriendly wizard, which would guide the user and provide functionality and with additional features such as exporting the archived reliability and rehabilitation results in Excel or text files for further investigation and analysis (Fig. 10.3).

A good example of replacement program was applied in Denizli, Turkey. In year 2003, Denizli Municipality evaluated the water balance of Denizli City,Turkey. The water balance was prepared as part of a project supported by the World Bank according to the IWA/AWWA methodology (Denizli City Water Works 2005). The results showed that there existed about $43 \%$ non-revenue water. Physical losses amounted up to $36 \%$. Because of these relatively high physical losses and water quality issues and also seismicity considerations, Denizli Municipality decided to speed up the pipe replacement efforts. Pipeline repair logs and complaints from the customers pointed to especially the pipelines located in the central part of the city. A comprehensive evaluation of the system following the elements of a distribution integrity management program (DIMP) plan showed that any replacement should have started from the central part of the city. And replacements program started in 2008. Ductile iron was selected as the pipe material. The replacement program is still continuing but in the first few years pipelines primarily in the liquefaction prone areas (e.g., Toprak et al. 2009) were renewed. Contractors obtained ductile iron pipes and their fittings mainly from two sources. One of them is the Samsun Makina Sanayi Inc. from Turkey and the other is the Saint-Gobain Group from France (Fig. 10.4a, b, respectively). Samsun Makina Sanayi Inc. produces special earthquake resistant type connections in order to avoid the deformation of the socket and pipe end. The socket parts of those pipes are manufactured with "long standard-type sockets", which has a longer design length than the standard manufactured pipes' sockets and inside the socket standard-type gasket is used together with the rubber backed steel ring, which prevents the pipe displacing from the socket. The groove opened to the end of the pipe prevents the pipe from displacing by attaching the steel ring. According to the Samsun Makina Inc. earthquake resistant type connection conforms the values mentioned in ISO 16134: 2006 (E) (Samsun Makina 2014).

- Expansion/Contraction performance: Class $\mathrm{S}-1 \pm \% 1$ of $\mathrm{L}$ (L is the length of pipe usually $6 \mathrm{~m}$ )

- Slip-out resistance: Class $\mathrm{A} \geq 3 \mathrm{D} \mathrm{kN}$ ( $\mathrm{D}$ is the nominal diameter of pipe),

- Joint deflection angle: $\mathrm{M}-2 \pm 7.5^{\circ}$ to $<15^{\circ}$.

BLUTOP is the patented name of the Saint-Gobain PAM Group ductile iron pipes which are designed to withstand a particularly high angular deviation of $6^{\circ}$. The enhanced jointing depth also decreases the risk of pipe dislocation. As a result, BLUTOP ${ }^{\circledR}$ offers excellent performance in soil subject to ground movements (Saint-Gobain-PAM 2014). 


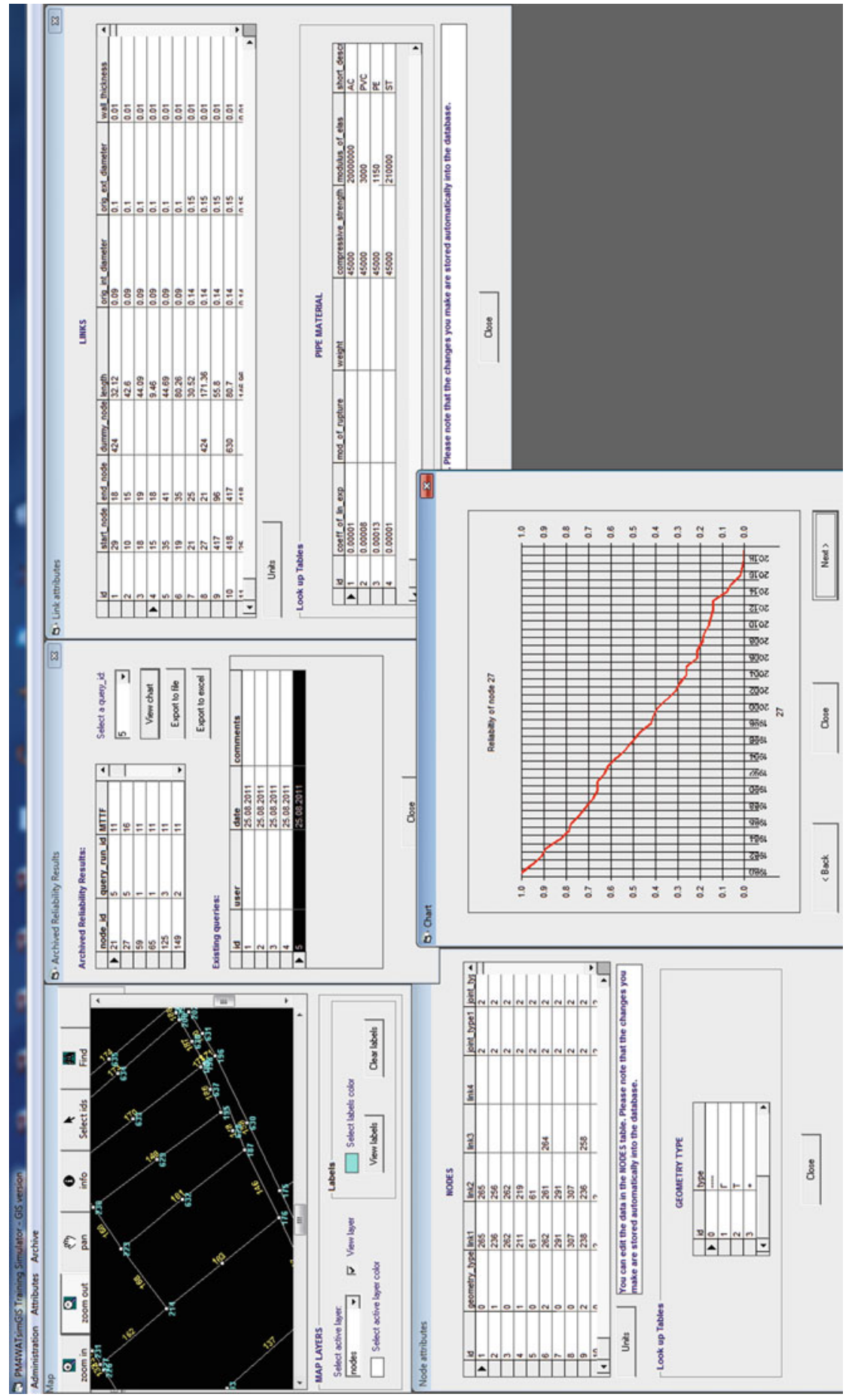

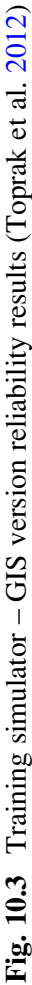



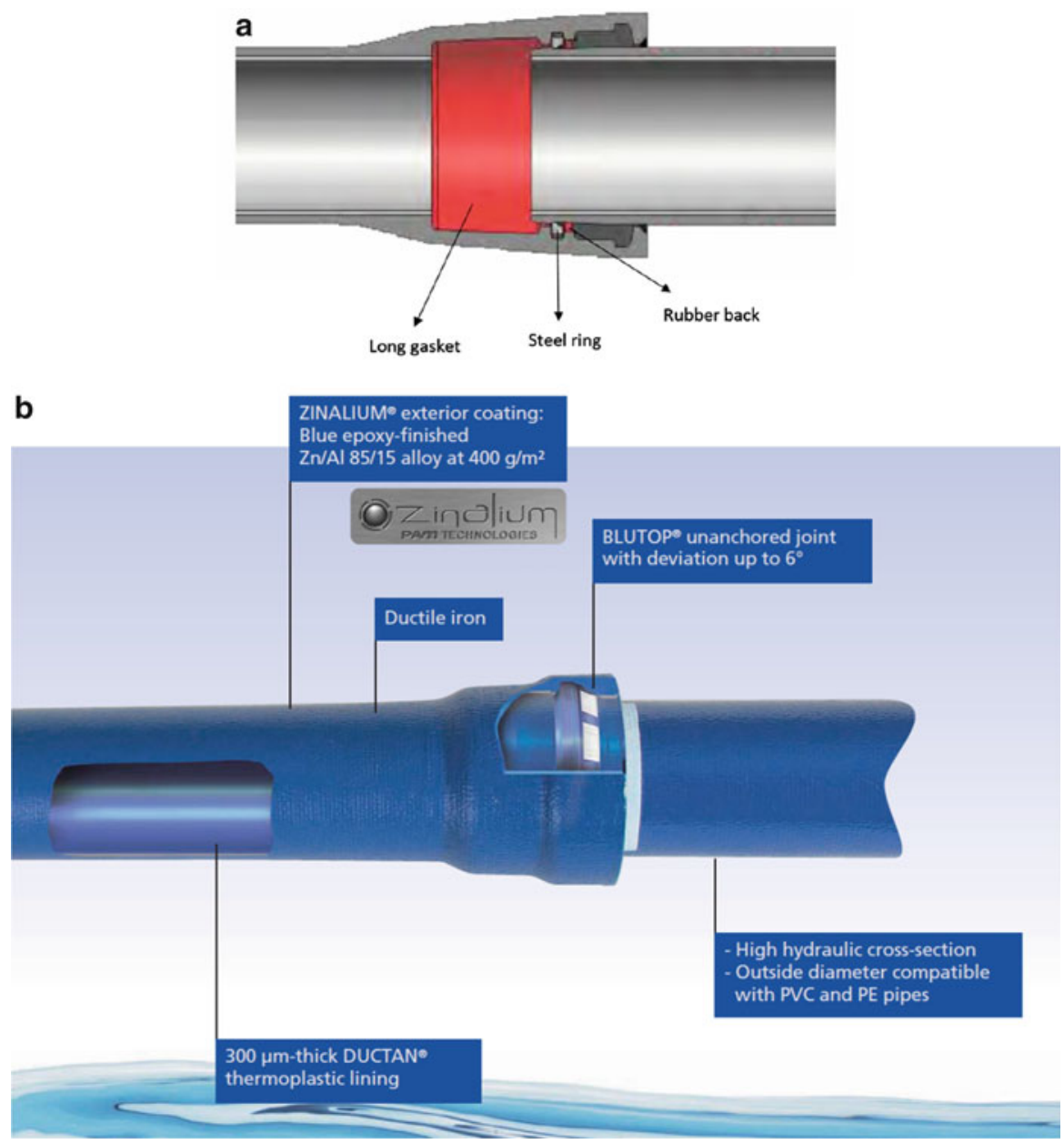

Fig. 10.4 Seismic joints used in Denizli, Turkey water pipelines replacement program. (a) Samsun Makina Sanayi Inc. earthquake resistant type connection. (b) The Saint-Gobain PAM BLUTOP® jointing

\subsection{Field Observations of Pipeline Damage and Ground Deformations}

Among the most notable research accomplishments in the last quarter of this century is the work of Hamada and coworkers (Hamada, et al. 1986; Hamada and O'Rourke 1992) in the use of stereo-pair air photos before and after an earthquake to perform photogrammetric analysis of large ground deformation. This process has influenced the way engineers evaluate soil displacements by providing a global view of deformation that allows patterns of distortion to be quantified and related to 
geologic and topographic characteristics. There are several examples where air photo measurements were used in pipeline damage assessment (e.g., Sano et al. 1999).

In recent years, light detection and ranging (LiDAR) data were being used to detect ground displacement hazards to pipeline systems. Stewart et al. (2009) investigated the use of multiepoch airborne and terrestrial LiDAR to detect and measure ground displacements of sufficient magnitude to damage buried pipelines and other water system facilities that might result, for example, from earthquake or rainfall-induced landslides. They concluded that observed LiDAR bias and standard deviations enable reliable detection of damaging ground displacements for some pipelines types.

Toprak et al. (2014) evaluated pipeline damages by using ground displacements from air photo and LiDAR measurements and made comparisons. High resolution LiDAR data were available through the Canterbury Earthquake Recovery Authority (CERA). Also horizontal and vertical displacements were available from stereopair air photos taken before and after the earthquakes to perform photogrammetric analysis of large ground deformations around Avonside area in Christchurch, NZ. Avonside area was in liquefaction zone.

Geospatial data in the form of GIS maps of the Christchurch water and wastewater distribution systems, locations of pipeline repair, and areas of observed liquefaction effects were integrated into a master GIS file. For the water supply systems, Toprak et al. (2014) study focuses on damage to water mains, which are pipelines with diameters typically between 75 and $600 \mathrm{~mm}$, conveying the largest flows in the system. It does not include repairs to smaller diameter submains and customer service laterals. The database was presented in detail and discussed in O'Rourke et al. (2012).

Figure 10.5 shows the water pipelines and repair locations in Avonside area. Also shown in the figure are air photo and LiDAR horizontal displacements. Measurements of lateral movement derived from the LIDAR surveys are provided as displacement in the east-west (EW) and north- south (NS) directions at 56-m intervals (CERA 2012). Horizontal displacements from air photo measurements are provided at 680 locations. There exist some benchmark displacement measurements in Christchurch area after the Canterbury earthquake sequence. Canterbury Geotechnical Database (CGD) provides about 403 benchmarks and their movement relative to earliest survey values after three big earthquakes. These data consist of information from Land Information New Zealand (LINZ 2014), Christchurch City Council, the Earthquake Commission (EQC) and CERA. There are 25 benchmarks from 403 benchmarks in Avonside area which are used in comparisons with LiDAR and air photos displacements.

For the purpose of horizontal strain calculations, the horizontal displacement data points are considered as corners of square elements. The grid with square elements may be regarded as a finite element mesh with bilinear quadrilateral elements. Knowing the coordinates of each corner and the corresponding displacement, the strains in the EW and NS directions ( $\varepsilon_{\mathrm{x}}$ and $\varepsilon_{\mathrm{y}}$, respectively) and shear strains $\left(\gamma_{\mathrm{xy}}\right)$ can be calculated by computing the spatial derivatives of displacements 


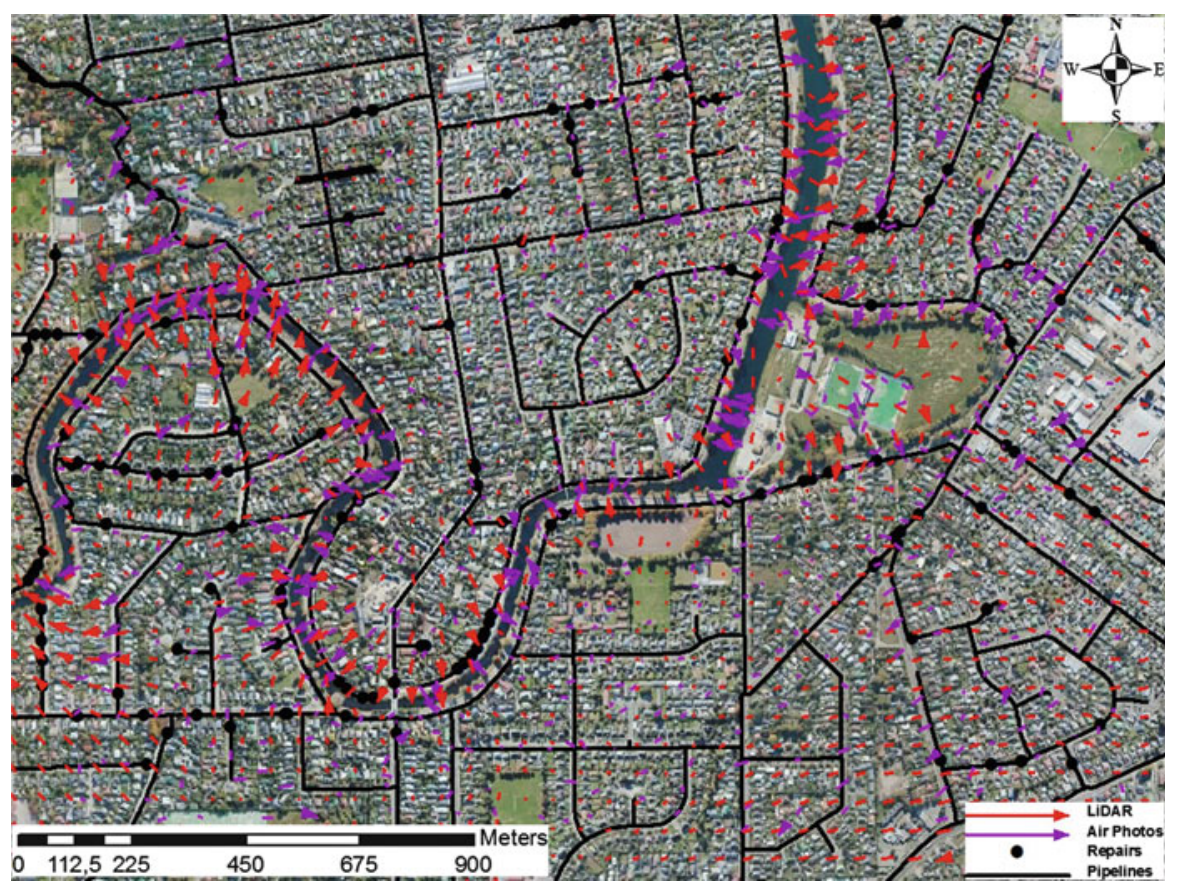

Fig. 10.5 Ground displacement from LiDAR and air photos superimposed on pipelines and pipe repairs in Avonside (Toprak et al. 2014)

using linear interpolation. Accordingly, finite element formulations were used to determine horizontal ground strains in the center of the elements, following the method described by Cook (1995). Pipeline repair rates (RRs), repairs/km, corresponding to different strain levels were calculated from air photo and LiDAR lateral movement measurements. Because RR represents damage normalized by available pipe length, the RRs are a good indicator of relative vulnerability (Toprak et al. 2009, 2011). The $\mathrm{r}$ squared values for the correlation between pipeline damage and lateral ground strains from LiDAR are higher than the correlation from air photo, indicating stronger correlation. The difference between the regressions is not so significant for lower strains and almost identical for higher strain values.

One of the most recent development in the pipeline damage correlations is to include the combined effects of horizontal ground strain and angular distortion. O'Rourke et al. (2012, 2014) developed the correlations for the 22 Feb. 2011 earthquake. This concept is used frequently in the evaluation of building damage caused by ground deformation from deep excavations and tunnelling. A figure correlating the severity of building damage with respect to horizontal strain and angular distortion was developed by Boscardin and Cording (1989) from field measurements and observations at actual buildings combined with the results of analytical models of building response to ground movements. This approach is used 
extensively to predict and plan for the effects of ground deformation on surface structures.

Angular distortion, $\beta$, is defined as the differential vertical movement between two adjacent LiDAR points $(\mathrm{dv} 1-\mathrm{dv} 2)$ divided by the horizontal distance, 1 , separating them, such that $\beta=(\operatorname{dv} 1-\operatorname{dv} 2) / 1$. It is used in this work to evaluate the effects of differential vertical movement on pipeline damage. There are several advantages associated with this parameter. First, it is dimensionless, and thus can be scaled to the dimensions appropriate for future applications. Second, by subtracting the vertical movements of two adjacent points, one eliminates some systematic errors associated with the LiDAR elevation surfaces. Finally, angular distortion is a parameter used widely and successfully in geotechnical engineering to evaluate the effects of ground deformation on buildings (e.g., Boscardin and Cording 1989; Clough and O'Rourke 1990). The angular distortion for each 5-m cell associated with the LiDAR measurements was calculated in the GIS analysis with a third order finite difference method proposed by Horn (1981). Correlations of RR for different pipe types vs. $\beta$ were shown in Fig. 10.6a.

Horizontal strain calculations $\left(\varepsilon_{\mathrm{HP}}\right)$ were performed according to the approach described above for Avonside area. Correlations of RR for different pipe types vs. $\varepsilon_{\mathrm{HP}}$ were shown in Fig. 10.6b. Figure 10.7 provides the framework for predicting $\mathrm{RR}$ for $\mathrm{AC}$ and $\mathrm{CI}$ pipelines under the combined effects of lateral strain and differential vertical ground movement. The correlation was performed by counting repairs and lengths of $\mathrm{AC}$ and $\mathrm{CI}$ pipelines associated with $\varepsilon_{\mathrm{HP}}$ and $\beta$ intervals of $1 \times 10^{-3}$. This type of chart expands on the correlations generally used for buried pipeline fragility characterization to provide a more comprehensive treatment of ground deformation effects. Moreover, it provides a unified framework for predicting PGD effects on both buildings and underground lifelines.

\subsection{Pipelines and Fault Crossings}

Many water, natural gas, and oil pipelines must cross active faults. Faults can be strike, reverse, and normal slip. When reverse and normal faulting involve significant components of strike slip, the resulting movement is referred to as oblique slip. Reverse and normal faults tend to promote compression and tension, respectively in underground pipelines. Strike-slip may induce compression or tension, depending on the angle of intersection between the fault and pipeline. The angle of pipeline-fault intersection is a critical factor affecting the pipeline's performance. Two applications of a pipeline crossing fault zone are presented below: one is above ground and the other underground.

Figure 10.8 shows Trans-Alaska Oil Pipeline, built in the 1970s crossing Denali Fault. The pipeline survived the 2002 Denali Fault earthquake without any break, only with some minor support damages. During the design phase it was estimated that the pipeline could be subjected to a magnitude 8.0 earthquake in which the ground might slip $20 \mathrm{ft}(6.1 \mathrm{~m})$ horizontally and $5 \mathrm{ft}(1.5 \mathrm{~m})$ vertically. To 

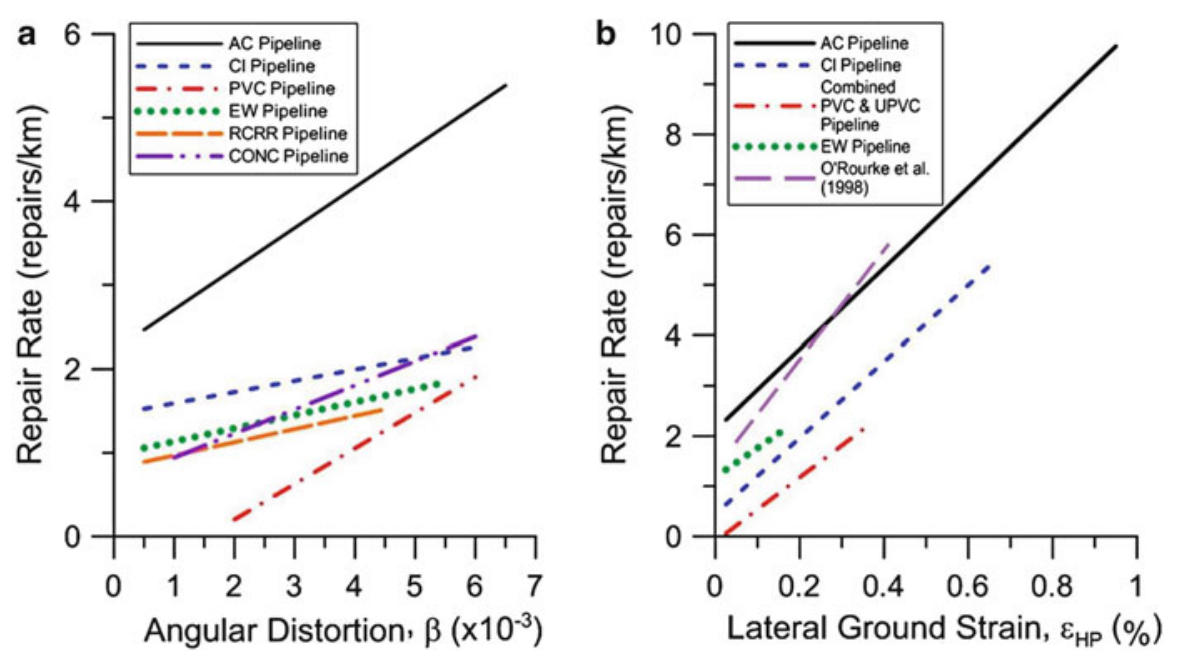

Fig. 10.6 Comparison of repair rate vs. angular distortion and lateral strain for different pipe types (O’Rourke et al. 2014)
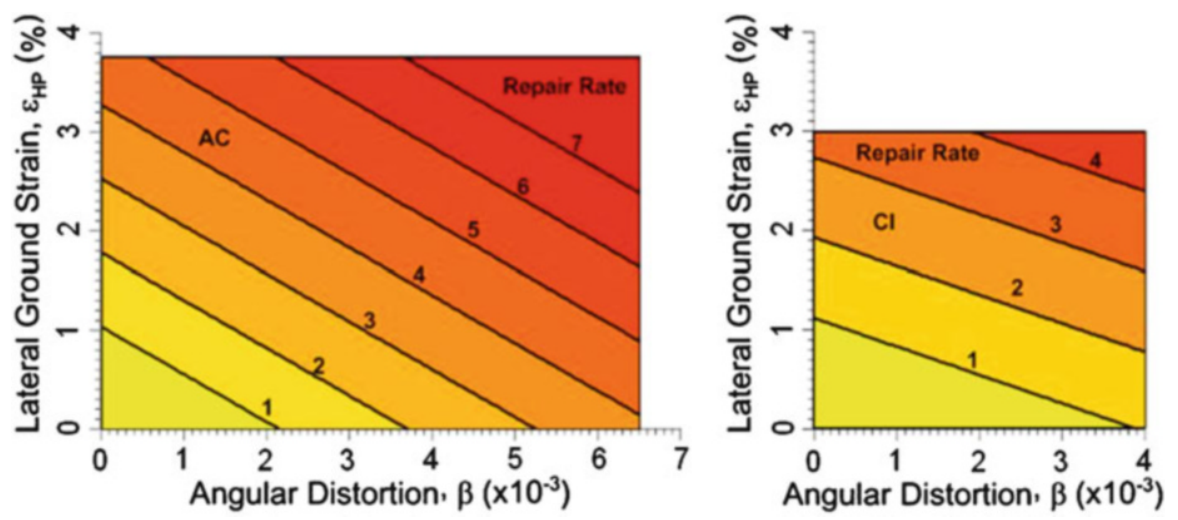

Fig. 10.7 Repair rate vs lateral strain, and angular distortion for AC and CI pipelines (O'Rourke et al. 2014)

accommodate the projected fault movement and intense earthquake shaking from a magnitude 8.0 quake, the zigzagging Trans-Alaska Oil Pipeline, where it crosses the Denali Fault, is supported on Teflon shoes that are free to slide on long horizontal steel beams. The design values proved to be remarkably accurate for the 2002 magnitude 7.9 earthquake and the fault shifted about $14 \mathrm{ft}(4.3 \mathrm{~m})$ horizontally and $2.5 \mathrm{ft}(0.75 \mathrm{~m})$ vertically. Such a prediction and the response is considered as success story for this vital pipeline which transports about $17 \%$ of the domestic oil supply for the United States (USGS 2003). 


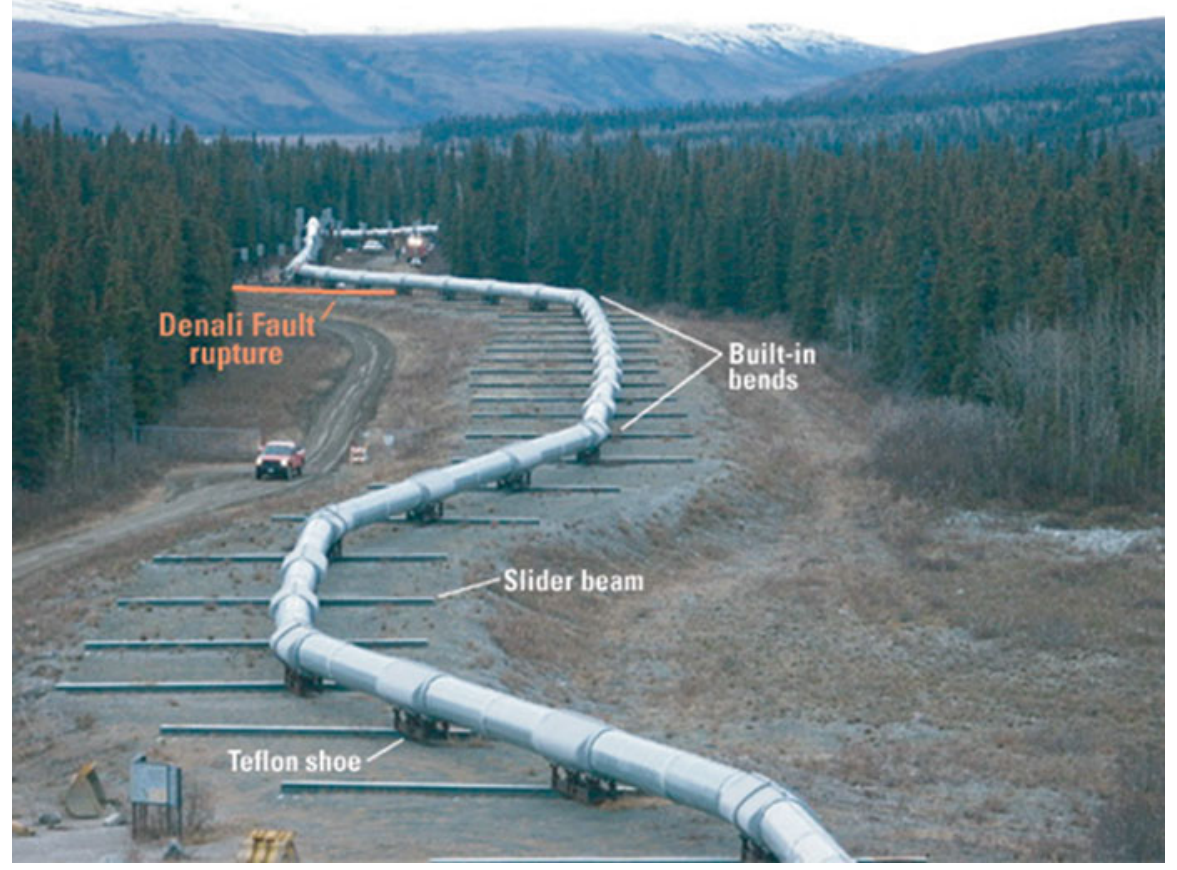

Fig. 10.8 Trans-Alaska Oil Pipeline and Denali Fault crossing (USGS 2003)

One of the recent pipeline construction projects which had to take into account seismic considerations is the Sakhalin 2 Pipeline Project. It is one of the largest integrated oil and gas developments in the world. Twin oil (20 and 24 in.) and gas (20 and 48 in.) pipeline systems stretching $800 \mathrm{~km}$ were constructed to connect offshore hydrocarbon deposits from the Sakhalin II concession in the North to an LNG plant and oil export terminal in the South of Sakhalin island. The onshore pipeline route follows a regional fault zone and crosses individual active faults at 19 locations (Mattiozzi and Strom 2008; Vitali and Mattiozzi 2014; Vitali 2014). A two-tier approach was adopted in the design: (1) The pipeline shall withstand the "Safe Level Earthquake" (SLE) without or with minimal interruption of normal operation for any extensive repairs. The return period for the SLE event shall be 200 years. (2) The pipeline shall survive the "Design Level Earthquake" (DLE) without rupturing. Extensive damage but no leakage could occur to the pipeline, which would interrupt operation and require repair at one or more locations. The return period for the DLE event shall be 1,000 years. Table 10.2 shows the design requirements for the buried pipelines.

For the fault crossings in the Sakhalin Project, special trenches were considered in order to ensure safety of the pipelines subject to the design earthquake. The trench geometry and the backfilling nature have been adapted to results from the stress analysis. Different trench types and backfill materials were utilized along the 
Table 10.2 Seismic design criteria for buried pipelines (API 5 L Grades X52 to X70), (Vitali 2014)

\begin{tabular}{l|l|l}
\hline Failure mode & $\begin{array}{l}\text { SLE criterion 200-year } \\
\text { event }\end{array}$ & $\begin{array}{l}\text { DLE criterion 1,000-year } \\
\text { event }\end{array}$ \\
\hline $\begin{array}{l}\text { Maximum tensile strain } \\
\text { (in bending) }\end{array}$ & $\varepsilon_{b} / \varepsilon_{M} \max \leq 0.90$ & $\varepsilon_{b} \leq 0.04(4.0 \%)$ \\
\hline $\begin{array}{l}\text { Collapse in compression/ } \\
\text { wrinkling }\end{array}$ & $\varepsilon_{a c} / \varepsilon_{w} \leq 0,80$ & $\varepsilon_{a c} / \varepsilon_{w} \leq 1.0$ \\
\hline Weld fracture & $\varepsilon_{a t} \leq 0.02(2.0 \%)$ & $\varepsilon_{a t} \leq 0.04$ \\
\cline { 2 - 3 } & $\sigma_{w} / \sigma_{y} \geq 1.25$ & $\sigma_{w} / \sigma_{y} \geq 1.25$ \\
\hline Upheaval buckling & $H_{f} / H_{s t} \geq 1.10$ & No requirement \\
\hline
\end{tabular}

$\varepsilon_{b}$ bending strain, $\varepsilon_{M \text { max }}$ strain at peak moment in moment vs. strain curve, $\varepsilon_{a c}$ net compressive strain due to axial load, $\varepsilon_{w}$ compressive strain at which wrinkling occurs, $\varepsilon_{a t}$ tensile strain in pipe, $\sigma_{w}$ minimum yield strength of weld/heat affected area, $\sigma_{y}$ specified minimum yield strength of pipe, $H_{f}$ actual burial depth, $H_{s t}$ burial depth needed for stability
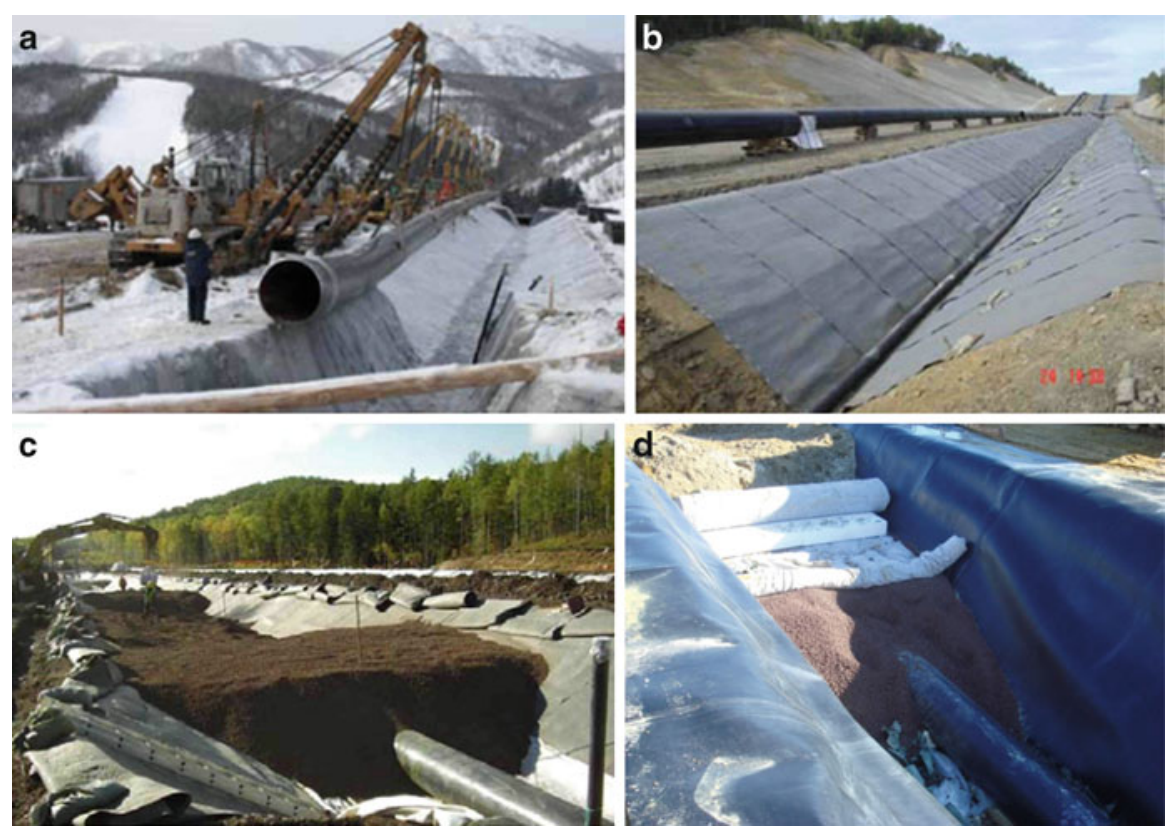

Fig. 10.9 Some pictures during construction of the special trenches. (a) Pipeline lowering in of the special trench. (b) Detail of sub-trench HDPE drainage pipe. (c) Backfilling of wide trenches with LECA (LBM). (d) Backfilling of narrow trenches with LECA (LBM) (Mattiozzi and Strom 2008; Vitali 2014)

pipeline route: "Draining Trenches" at 2 fault crossings, "Waterproof Trench" at 13 fault crossings, and "Waterproof Trench in Embankment" at 4 fault crossings (Fig. 10.9). To avoid freezing, two important factors were controlled inside the trench: (a) Absence of water; (b) Thermal equilibrium. The first aspect is controlled 
with the construction of either waterproof or free draining trenches; the second is controlled with the installation of insulating slabs over the pipelines, within the trench. In order to minimize the types and dimensions of special trenches, for each fault crossing, two trench geometries were adopted: (a) Narrow trench; (b) Enlarged trench. Also for the trench backfill material, two solutions were proposed: (a) Clean sand backfill, (b) Light backfill material (LBM).

\subsection{Conclusions}

In this paper, recent developments related to assessment of seismic performance of buried pipelines are presented. The experience from the performance of pipelines during last earthquakes provided invaluable information and lead to new developments in the analysis. Some earthquake resistant design and technologies proved to be working in those earthquakes. This provides a motivation to increase international exchange and cooperation on earthquake resistant technologies. Another observation is that pipeline monitoring and mitigation studies are important to reduce the pipeline damage risk from seismic and other hazards. To increase the applicability and sustainability, seismic improvements should be incorporated into the pipe replacement and asset management programs. However, it is also important to put in the most proper pipeline from the start as replacing or retrofitting the pipelines later requires substantial investment. In this respect, seismic considerations should be taken into account properly in the design phase. Sufficient considerations should be given regarding the pipe materials, joints and soil-pipe interaction from the life expectancy and hazards points of view.

Acknowledgements This study was partly supported by the European Commission with the Leonardo Da Vinci Project numbered as CZ/13/LLP-LdV-TOI/134014 and by TUBITAK with project no 114M258. This publication reflects the views only of the authors, and the Commission and TUBITAK cannot be held responsible for any use which may be made of the information contained therein. Special thanks go to Luigino Vitali, Manager, Sealines Engineering Department, SAIPEM, Italy for providing information about the Sakhalin 2 Pipeline Project.

Open Access This chapter is distributed under the terms of the Creative Commons Attribution Noncommercial License, which permits any noncommercial use, distribution, and reproduction in any medium, provided the original author(s) and source are credited.

\section{References}

ALA (2001) Seismic fragility formulations for water systems. Part 1 - Guideline. American Lifelines Alliance (ALA), ASCE-FEMA, $104 \mathrm{p}$.

Becker G, Camarinopoulos L, Kabranis D (2002) Dynamic reliability under random shocks. Reliab Eng Syst Safe 77:239-251 
Boscardin MD, Cording EJ (1989) Building response to excavation-induced settlement. J Geotech Eng ASCE 115(1):1-21

Camarinopoulos L, Frondistou M, Kallidromitis V, Syrmakezis C, Sophocleous A (2001) Report on a methodology for the quantitative assessment of the time-dependent seismic structural reliability of deteriorating water-pipes version 2, SEISLINES (Age-Variant Seismic Structural Reliability of Existing Underground Water Pipelines). Commission of the European Communities, DG XII, Contract Reference: EVG1-CT-1999-00005

Canterbury Earthquake Recovery Authority (CERA) (2012) Geotechnical database for Canterbury earthquake sequence. https://canterburygeotechnicaldatabase.projectorbit.com

Chen WW, Shih BJ, Chen YC, Hung JH, Hwang HH (2002) Seismic response of natural gas and water pipelines in the Ji-Ji earthquake. Soil Dyn Earthq Eng 22:1209-1214

Clough GW, O'Rourke TD (1990) Construction induced movements of in-situ walls. Proceedings, specialty conference on design and performance of earth retaining structures, ASCE, pp $439-470$

Cook RD (1995) Finite element modeling for stress analysis. Wiley, New York

Davis C (2012) Concepts for distribution pipe network seismic improvements in L.A. and proposed pilot project for Japanese designed earthquake resistant ductile iron pipe. Earthquake and multi-hazard planning and preparedness symposium and workshop, 22 Mar 2012, Los Angeles

Denizli City Water Works (2005) Denizli Municipality. Denizli. http://www.denizli.bel.tr/

Eidinger J (1998) Water distribution system - The Loma Prieta, Californa, Earthquake of October 17, 1989 - Lifelines, USGS, Professional Paper 1552-A, Schiff AJ (ed) U.S. Government Printing Office, Washington, A63-A78

Hamada M, O'Rourke TD (eds) (1992) Case studies of liquefaction and lifeline performance during past earthquakes. Technical Report NCEER-92-0001, National Center for Earthquake Engineering Research, State University of New York at Buffalo

Hamada M, Yasuda S, Isoyama R, Emoto K (1986) Study on liquefaction induced permanent ground displacement. Association for the Development of Earthquake Prediction, Tokyo

Horn BKP (1981) Hill shading and the reflectance map. Proc IEEE 69(1):14-47

Hwang H, Chiu YH, Chen W, Shih BJ (2004) Analysis of damage to steel gas pipelines by ground shaking effects during the Chi-Chi, Taiwan Earthquake. Earthq Spectra 20(4):1095-1110

International Standard (ISO) 16134: 2006 Earthquake- and subsidence-resistant design of ductile iron pipelines. Edition: 1, ICS: 23.040.10, TC/SC: ISO/TC 5/SC 2, Published in Switzerland, $32 \mathrm{p}$.

Land Information New Zealand (LINZ, 2014) http://apps.linz.govt.nz/gdb/index.aspx? nextform $=$ image $\&$ image_id $=108377 \&$ mode $=\&$ sessionid $=115555239158881397733794 \&$ code $=$ BDVB

Mattiozzi P, Strom A (2008) Crossing active faults on the Sakhalin II Onshore pipeline route: pipeline design and risk analysis. AIP Conf Proc 1020:1004

Miyajima M (2012) The 9th international symposium on water supply technology, 20-22 November 2012, Yokohama

O'Rourke M, Deyoe E (2004) Seismic damage to segmented buried pipe. Earthq Spectra 20:1167-1183

O'Rourke TD, Jeon SS (1999) Factors affecting the earthquake damage of water distribution systems, optimizing post-earthquake lifeline system reliability. In: Elliott WM, McDonough P (eds) Proceedings, fifth U.S. conference on lifeline earthquake engineering. ASCE, Seattle, pp 379-388

O’Rourke TD, Jeon SS (2000) “Seismic zonation for lifelines and utilities” Invited Keynote Paper on Lifelines. Proceedings sixth international conference on seismic zonation, Palm Springs, EERI CD ROM, $35 \mathrm{p}$

O'Rourke TD, Toprak S (1997) GIS assessment of water supply damage from the Northridge Earthquake. In: Frost JD (ed) Geotechnical special publication. ASCE, New York, pp 117-131 
O'Rourke TD, Toprak S, Sano Y (1998) Factors affecting water supply damage caused by the Northridge earthquake. Proceedings of 6th U.S. National conference on earthquake engineering, EERI, Oakland

O’Rourke TD, Jeon SS, Toprak S, Cubrinovski M, Jung JK (2012) Underground lifeline system performance during the Canterbury Earthquake Sequence. 15th world conference in earthquake engineering, Lisbon, Portugal

O'Rourke TD, Jeon SS, Toprak S, Cubrinovski M, Hughes M, Ballegooy S, Bouziou D (2014) Earthquake response of underground pipeline networks in Christchurch, NZ. Earthquake Engineering Research Institute, EERI

Pineda-Porras O, Najafi M (2010) Seismic damage estimation for buried pipelines: challenges after three decades of progress. J Pipeline Syst Eng Pract 1(1):19-24

Saint-Gobain-PAM (2014) http://www.saint-gobain-pam.co.uk/water-sewer/pipes-and-fittings/ water/blutop.htm

Samsun Makina (2014) http://www.samsunmakina.com.tr/_tu/_docs/ddb.html

Sano Y, O'Rourke TD, Hamada M (1999) GIS evaluation of Northridge earthquake ground deformation and water supply damage. Proceedings of fifth U.S. Conference on lifeline earthquake engineering, TCLEE Monograph No. 16, ASCE, pp 832-839

Scawthorn C, Ono T, Iemura H, Ridha M, Purwanto B (2006) Performance of lifelines in Banda Aceh, Indonesia, during the December 2004 Great Sumatra Earthquake and Tsunami. Earthq Spectra 22(S3):S511-S544

Stewart JP, Hu J, Kayen RE, Lembo AJ Jr, Collins BD, Davis CA, O’Rourke TD (2009) Use of airborne and terrestrial LIDAR to detect ground displacement hazards to water systems. J Surv Eng 135(3):113-124

Toprak S (1998) Earthquake effects on buried lifeline systems, Ph.D. Thesis, Cornell University, Ithaca

Toprak S, Koç AC (2013) Contribution of Leonardo Projects to Education in Technical Fields, Pamukkale University. Journal Of Education, No.33, (January 2013/I), s. 73-91

Toprak S, Taşkın F (2007) Estimation of earthquake damage to buried pipelines caused by ground shaking. Nat Hazards (Springer, The Netherlands) 40:1-24

Toprak S, Koç AC, Taskin F (2007) Evaluation of water distribution pipeline performance against earthquakes. Paper No: 1748, 4th international conference on earthquake geotechnical engineering, Paper No: 1748, Thessaloniki, 25-28 June 2007

Toprak S, Taskin F, Koç AC (2009) Prediction of earthquake damage to urban water distribution systems: a case study for Denizli, Turkey. Bull Eng Geol Environ 68:499-510

Toprak S, Nacaroğlu E, Koç AC (2011) Seismic damage probabilities for segmented buried pipelines. In: Faber MH, Köhler J, Nishijima K (eds) Applications of statistics and probability in civil engineering. ETH Zurich, Zurich, pp 2199-2203

Toprak S, Koç AC, Güngör M, Kaya M, Stathaki A (2012) Application of a training project in Turkey on preventive maintenance of water utility networks against earthquakes. Paper No. 5673, 15th world conference on earthquake engineering (15WCEE), Lisbon, 24-28 Sept 2012

Toprak S, Nacaroğlu E, O’Rourke TD, Koç AC, Hamada M, Cubrinovski M, Jeon SS (2014) Pipeline damage assesment using horizontal displacements from air photo and LiDAR measurements Avonside Area, Christchurch, NZ. The second European conference on earthquake engineering and seismology (2ECEES), 24-29 Aug 2014

Trifunac MD, Todorovska MI (1997) Northridge, California, earthquake of 17 January 1994: density of pipe breaks and surface strains. Soil Dyn Earthq Eng 16(3):193-207

Tromans I, Marlow D, Bommer J (2004) Spatial distribution of pipeline damage in Düzce caused By the 1999 Kocaeli and Düzce Earthquakes. Paper No. 2916, 13th world conference on earthquake engineering, Vancouver, 1-6 Aug

Tsakiris G, Vangelis H, Tigkas D, Stathaki A, Sofotasios D, Toprak S, Koç AC, Gungor M, Kaya M, DeAngelis E, Iacovou G (2011) Preventive maintenance for water utilities. VI international symposium EWRA 2011, water engineering and management in a changing environment, Catania, June 29-July 22011 
USGS (U.S. Geological Survey) (2003) Rupture in South-Central Alaska - the Denali Fault Earthquake of 2002. USGS Fact Sheet 014-03, Menlo Park. http://geopubs.wr.usgs.gov/factsheet/fs014-03/

Vitali L (2014) Pipeline design in harsh environments-geohazards; strainnbased design at local features across artic regions. Geohazards and pipelines, Safety of buried steel pipelines underground-induced actions Delft Technology University, Delft

Vitali L, Mattiozzi P (2014) Crossing active faults on the Sakhalin II Onshore pipeline route: analysis methodology and basic design. AIP Conf Proc 1020:1014

Yifan Y, Baitao S, Shanyou L, Mingyu Z, Dezhang S, Guixin Z, Hongfu C, Peilei Y, Xianghua C, Peng Z, Zairong W, Zhihong W (2008) General introduction of engineering damage of Wenchuan Ms8.0 earthquake. J Earthquake Eng Eng Vibration 28(Suppl):1-16 